\title{
A SILAGEM DE PESCADO NA ALIMENTAÇÃO DE ORGANISMOS AQUÁTICOS
}

RICARDO BORGHESI*

LIA FERRAZ DE ARRUDA* MARÍLIA OETTERER**

\begin{abstract}
O objetivo deste trabalho foi conhecer o potencial da silagem de pescado como ingrediente alternativo à farinha de peixe, principal fonte protéica, em rações para a aqüicultura com base na literatura nacional e internacional. A revisão abordou os aspectos bioquímicos e nutricionais, as metodologias de produção e o uso da silagem na alimentação de organismos aquáticos, bem como os resultados de diversas pesquisas. É viável a utilização da silagem de pescado como ingrediente (alternativo) potencial em rações para aqüicultura e, portanto, as investigações científicas devem prosseguir neste sentido.
\end{abstract}

PALAVRAS-CHAVE: RESÍDUOS; SILAGEM; PROTEÍNA; NUTRIÇÃO; PEIXES.

* Mestres em Ciência e Tecnologia de Alimentos, Departamento de Agroindústria, Alimentos e Nutrição, Universidade de São Paulo (USP), Piracicaba, SP (e-mail: ricardo_borghesi@yahoo.com.br).

** Professora Titular, Departamento de Agroindústria, Alimentos e Nutrição, USP, Piracicaba, SP (moettere@esalq.usp.br). 


\section{INTRODUÇÃO}

O crescimento da aqüicultura, associado ao aumento de práticas de cultivo cada vez mais intensivas, vem gerando aumento na procura por alimentos de alta qualidade que permitam formular dietas de alto valor nutricional, economicamente viáveis e ambientalmente corretas.

Na piscicultura, como em qualquer criação zootécnica, a alimentação representa alto percentual dos custos operacionais (em torno de 40 a 60\%), sendo os ingredientes protéicos responsáveis pela maior parte desse custo (EL-SAYED, 1999; CHENG, HARDY e USRY, 2003).

A farinha de peixe tem sido, durante anos, a fonte protéica de origem animal mais utilizada em dietas balanceadas para peixes. É considerada indispensável para a obtenção de crescimento adequado, devido ao seu alto valor biológico, além de atuar como palatabilizante (FURUYA, 2000; PEZZATO, 1995; SALES e BRITZ, 2003).

Estudos mostram progressiva escassez da farinha de peixe no mercado mundial e o conseqüente aumento relativo em seu preço (NEW e CSAVAS, 1995). Com isso a produção de ração comercial de qualidade para a aqüicultura dependerá em futuro próximo da elaboração de produtos adequados para substituição da farinha de peixe, tanto sob o aspecto nutricional quanto de custo. Diversas pesquisas vêm sendo realizadas no sentido de identificar fontes protéicas alternativas, disponíveis nas regiões de criação, como substitutos parciais ou totais da farinha de peixe para permitir redução nos custos com alimentação (FURUYA, 2000; PORTZ, 2001).

Os resíduos de origem animal representam vasta fonte de energia e de nutrientes, que podem ser convertidos em ingredientes para a indústria de alimentação animal. Alternativa com grande potencial é o aproveitamento das perdas de captura e resíduos do processamento do pescado (que podem chegar a $60 \%$ do total que é produzido e/ou capturado) para a elaboração do ensilado de peixe, produto nobre e com alto valor biológico (BEERLI, BEERLI e LOGATO, 2004; CARVALHO et al., 2006; VIDOTTI, VIEGAS e CARNEIRO, 2002; VIDOTTI et al., 2003).

Acredita-se que o grau de hidrólise pode ser usado como critério químico para avaliar a qualidade da silagem de pescado (ESPE, RAA e NJAA, 1989; ESPE e LIED, 1999). Segundo STONE et al. (1989), o valor nutricional da silagem pode ser significantemente aumentado limitando a hidrólise das proteínas e polipeptídeos em aminoácidos livres. Citam que, assim como em humanos, os peptídeos de cadeia curta (di e tripeptídeos) são melhores e mais absorvidos pelos peixes que os aminoácidos livres.

Muitos autores acreditam que a silagem apresenta elevado potencial para a utilização na aqüicultura pela sua semelhança com a matéria-prima, fornecendo proteínas de boa qualidade, alta digestibilidade e baixo custo. Além disso, há o benefício ambiental, pois o resíduo de pescado descartado resulta em matéria poluente (FAGBENRO, 1994; FAGBENRO e JAUNCEY, 1995a, 1995b; GODDARD e AL-YAHYAI, 2001; VIDOTTI, CARNEIRO e VIEGAS, 2002).

É de grande relevância a inserção do aproveitamento de resíduos na cadeia produtiva de pescado com intuito de evitar desperdícios, reduzir os custos de produção do pescado e diminuir a poluição ambiental. A criação de alternativas tecnológicas nesse sentido trará como resultado a geração de empregos e indicará o caminho para o desenvolvimento sustentado.

O objetivo deste trabalho foi avaliar o potencial da silagem de pescado como ingrediente alternativo à farinha de peixe, principal fonte protéica, em rações para a aqüicultura com base na literatura nacional e internacional.

\section{A SILAGEM DE PESCADO}

A ensilagem de resíduos de pescado constitui técnica antiga de preservação da matéria orgânica (SHIRAl et al., 2001). A metodologia para preservação do resíduo de pescado foi adaptada por Edin na década de 30, a partir do método patenteado por Virtanen na década de 20, que utilizava os ácidos sulfúrico e clorídrico para preservação de forragens (RAA e GILBERG, 1982). 
Sua produção comercial ocorre apenas na Dinamarca, Polônia e Noruega, desde a década de 40 (SALES, 1995).

A silagem de pescado constitui produto liquefeito, produzido a partir do pescado inteiro ou partes dele. A preservação do material ensilado ocorre mediante redução do $\mathrm{pH}$ pela adição de ácidos orgânicos e/ou minerais (silagem ácida) ou adição de microrganismos produtores de ácido lático (silagem biológica), ou pela combinação dos dois métodos. Além de prevenir a ação microbiana e não atrair insetos, o abaixamento do pH propicia a ação das enzimas naturalmente presentes no pescado e/ou adicionadas (silagem enzimática), geralmente pepsinas e catepsinas. Tais enzimas são responsáveis pela hidrólise protéica, originando produto rico em proteínas, peptídeos de cadeia curta e aminoácidos livres (GODDARD e PERRET, 2005; KOMPIANG, 1981; STONE e HARDY, 1986; VALÉRIO, 1994).

A liquefação que ocorre durante o processo de ensilagem resulta da hidrólise enzimática. Presume-se também que a autólise em silagens preparadas com o pescado inteiro ocorre, principalmente, devido às enzimas das vísceras que são distribuídas pela massa do peixe após a moagem. A liquefação da silagem é marcadamente favorecida em meio ácido e em temperaturas acima da média ambiente (OETTERER, 1994).

KOMPIANG (1981) aponta as seguintes vantagens para a produção de silagem sobre a produção de farinha de pescado: tecnologia simples, independe de escala, não necessita de grande capital, apresenta reduzidos problemas com odor e efluentes, independe do clima, pode ser produzida a bordo dos barcos, o processo é rápido em regiões de clima tropical e o produto pode ser utilizado no local. As desvantagens indicadas pelo autor envolvem o volume do produto, seu difícil transporte e armazenamento e, em alguns casos, qualidade inferior do produto final devido ao alto teor de gordura.

A fermentação microbiana pode ocorrer no pescado, desde que seja adicionada fonte de carboidratos à biomassa. As bactérias produtoras de ácido lático propiciarão sua preservação pela produção de ácido lático e conseqüente abaixamento do pH (OETTERER, 1994), inibindo o crescimento de bactérias como Staphylococcus, Escherichia, Serratia, Enterobacter, Citrosacter, Achromobacter e Pseudomonas (DAPKEVICIUS et al., 2000). Além da acidez, acredita-se que a habilidade de certas bactérias ácido láticas em produzir compostos antibacterianos (chamados bacteriocinas), colaboram na inibição do crescimento de microrganismos patogênicos (BORRENSEN, 1990).

ZAHAR et al. (2002) estudaram o efeito da temperatura, anaerobiose e agitação da massa na produção de silagens biológicas, utilizando como fonte de carboidrato o melaço de cana. Afirmaram que a fermentação natural é acelerada quando conduzida em temperatura ambiente $\left(25 \pm 2^{\circ} \mathrm{C}\right)$, recipientes fechados e agitação diária da massa.

VIDOTTI (2001) preparou silagens biológicas e ácidas a partir de diferentes matérias-primas. Verificou que além de viáveis, os processos utilizados para a preservação do resíduo de pescado mantêm a qualidade protéica dos produtos.

Preparando silagens biológicas com $5 \%$ de iogurte e $10 \%$ de melaço de cana, BERENZ (1994) obteve produto com $63,32 \%$ de umidade e $18,46 \%$ de proteína bruta (base úmida). Testou o produto obtido na alimentação de frangos de corte e afirmou que a silagem pode ser utilizada como fonte protéico-energética em rações sem perda do desempenho e da qualidade da carcaça.

Vários autores (GODDARD e AL-YAHYAI, 2001; KOMPIANG, 1981; MORALES-ULLOA, 1994; VALÉRIO, 1994) recomendam a mistura de ácidos fórmico e propiônico na proporção de 1:1 e adição de 1,5 a 3,0\% (v/p) em relação à massa, visando a obtenção de silagem estável e livre de microrganismos patógenos.

\section{VALOR NUTRICIONAL DA SILAGEM}

Apesar das alterações nas estruturas física e química do peixe, o valor nutricional da silagem assemelha-se ao material que lhe deu origem. No entanto, varia consideravelmente conforme 0 tipo de matéria-prima empregada, particularmente quanto ao teor de lipídios (DISNEY et al., 1977; KOMPIANG, 1981). Na Tabela 1 está apresentada a composição de vários tipos de silagens produzidas a partir de diferentes matérias-primas. 


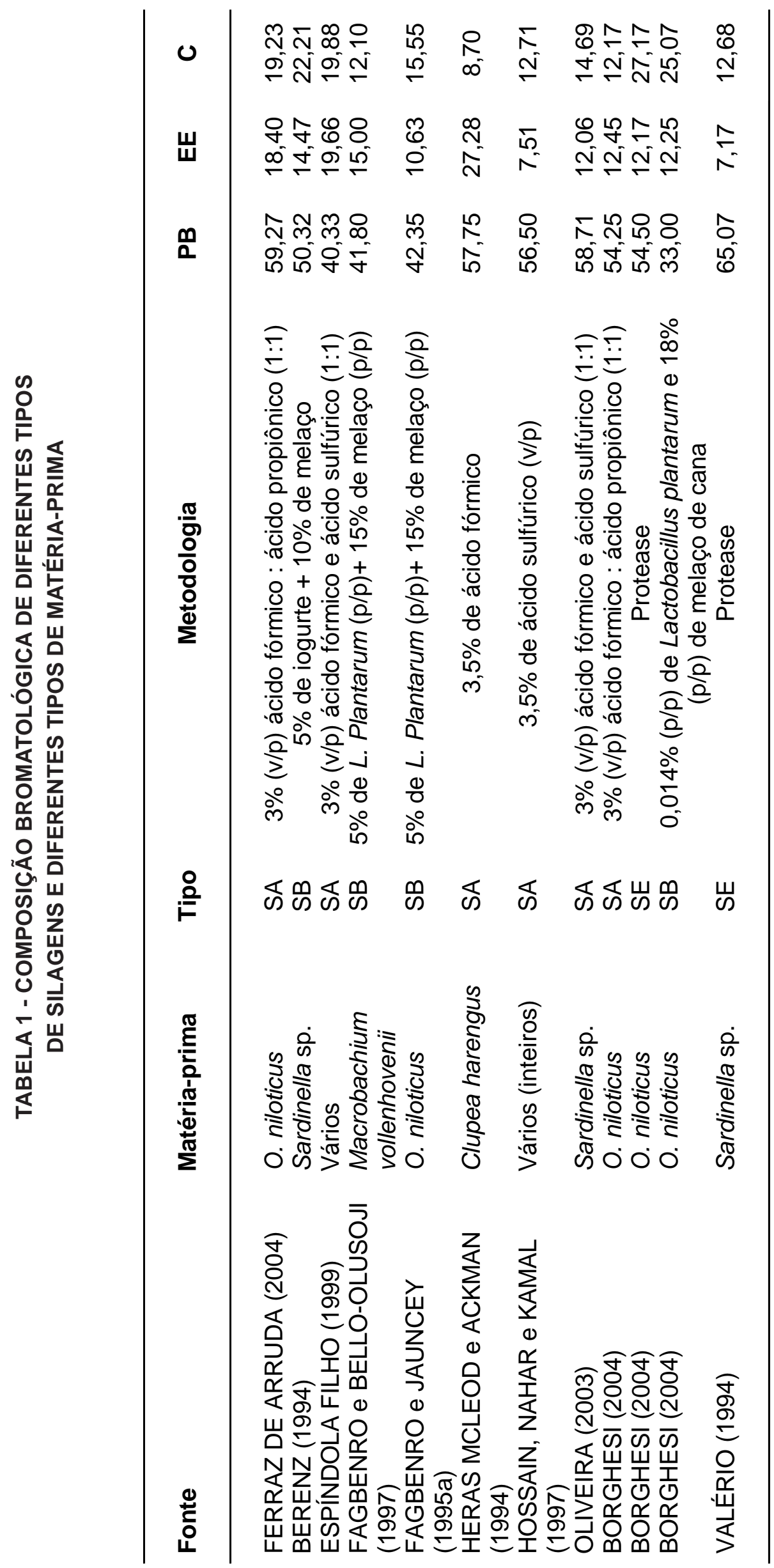


Pode-se observar que a composição centesimal varia de uma espécie de pescado para outra e até entre a mesma espécie, dependendo da época do ano, tipo de alimentação, grau de maturação gonadal e sexo. Além disso, pode apresentar variação no mesmo peixe, dependendo da parte analisada (SALES,1995). Como a composição da silagem é muito semelhante à matériaprima, o valor nutricional da silagem também varia segundo os fatores citados.

Durante o armazenamento prolongado, grande número de aminoácidos livres está presente na silagem devido à atividade das enzimas endógenas. A hidrólise prolongada, no entanto, pode resultar na redução do valor nutricional da silagem. Para evitar a hidrólise excessiva durante armazenamento prolongado, as enzimas presentes no pescado podem ser inativadas pelo aquecimento da matéria-prima por 5 minutos a $60^{\circ} \mathrm{C}$ antes da ensilagem. Tal aquecimento resulta na redução de 15\% no nível de aminoácidos livres, após 90 dias quando comparada com silagem não-aquecida (VIANA, GUZMAN e ESCOBAR, 1999).

De acordo com OETTERER (1999), o valor nutricional da silagem está na elevada digestibilidade protéica que deve ser preservada, evitando-se armazenamento prolongado e, portanto, hidrólise excessiva. GODDARD e AL-YAHYAI (2001) e STONE et al. (1989) citam que controlando-se a hidrólise protéica, o valor nutricional do produto final do processo de ensilagem é superior ao excessivamente hidrolisado. Isto porque os peptídeos de cadeia curta são mais facilmente absorvidos que os aminoácidos livres.

Explicação provável para a redução do valor nutricional pode ser o fato dos aminoácidos livres serem rapidamente desviados da síntese protéica e entrarem na rota catabólica. Assim, os aminoácidos livres estão mais disponíveis para serem utilizados como fonte de energia do que as proteínas intactas (ESPE, RAA e NJAA, 1989). Os aminoácidos livres na presença de hidroxilas provenientes do açúcar apresentam a reação de Maillard resultando na diminuição do valor nutricional da silagem (FAGBENRO, 1994; FAGBENRO e JAUNCEY, 1998).

De acordo com STONE e HARDY (1986), altos níveis de aminoácidos livres na dieta interferem no mecanismo de absorção de aminoácidos e peptídeos de cadeia curta. Os peptídeos de cadeia curta quando absorvidos reduzem as flutuações do nível de aminoácidos no plasma e retornam disponíveis para a síntese protéica por períodos mais longos do que os aminoácidos livres.

KOMPIANG (1981) destaca que o aumento no tempo de armazenamento baixa a eficiência de conversão, sendo o valor nutricional afetado negativamente. Afirmou que há relação direta entre o escurecimento provocado por reações dos lipídios e a perda do valor nutritivo. Outro fator importante na deterioração da qualidade das silagens armazenadas por longos períodos é o processo de oxidação lipídica, resultando em alterações de sabor, cor, textura e valor nutricional, além da produção de componentes tóxicos. Quando as proteínas são expostas a lipídios peroxidados, porção considerável desses complexa-se com proteínas mediante associações e/ou ligações de hidrogênio causando perda do valor nutritivo (SALES, 1995).

Ligações covalentes entre produtos oxidados e proteínas podem destruir aminoácidos como triptofano, oxidar a metionina e ligar a lisina a outros compostos tornando esses aminoácidos indisponíveis (NELSON e COX, 2000).

TOCHER, MOURENTE e SARGENT (1997) demonstraram que silagens preparadas com tecidos que compõem o sistema nervoso de peixes são ricos em fosfolipídios e triglicerídeos, dependendo da espécie e do tecido (cérebro). De acordo com esses autores, a fração lipídica das silagens produzidas com esses tecidos (sistema nervoso) continha altos níveis de docosahexaenóico e alta proporção de docosahexaenóico : eicosapentaenóico.

FERRAZ DE ARRUDA (2004) avaliou o perfil de ácidos graxos de silagem ácida de tilápia do Nilo. Encontrou predominância dos ácidos graxos insaturados, sendo que o oléico (C18:1) apresentouse em maior quantidade (28,60 g/100 g de óleo). Verificou apenas traços dos ácidos graxos eicosapentaenóico (EPA - C20:5) e docosahexaenóico (DHA - C22:6). Já ESPÍNDOLA FILHO (1999) obteve valores de 1,1 g/100 g de óleo para o EPA e 1,1 g/100 g de óleo para o DHA, estudando silagem ácida com 60 dias de armazenamento e produzida a partir de diferentes matéria-primas. 
Avaliando a composição química e a qualidade nutricional das silagens ácida (SA), biológica (SB) e enzimática, elaboradas do descarte de tilápia do Nilo (Oreochromis niloticus), BORGHESI (2004) encontrou valores (base na matéria seca) de: 54,25; 33,00 e 54,50 g/100 g para a proteína bruta; 12,$45 ; 12,25$ e 12,17 g/100 g para lipídeos; 8,03; 7,33 e 8,58 g/100 g para o cálcio e 4,71; 2,86 e 4,85 g/100 g para o fósforo, respectivamente para SA, SB e SE. Os três tipos de silagem apresentaram todos os aminoácidos essenciais (AAE). Entre os AAE, em geral, a leucina $(3,50$; 2,41 e 3,31 g/100 g para SA, SB e SE, respectivamente) e a lisina (3,33; 2,41 e 3,22 g/100 g para SA, SB e SE, respectivamente) apresentaram-se em maior concentração nas silagens.

VIDOTTI, VIEGAS e CARNEIRO (2003) avaliaram a composição em aminoácidos de silagens biológicas e ácidas preparadas com diferentes matérias-primas, mediante escore químico e usando como padrão as exigências em aminoácidos essenciais para tilápia do Nilo. Consideraram a silagem como produto sem aminoácidos limitantes e, portanto, apropriada para ser usada em dietas para a tilápia.

Na Tabela 2 pode-se comparar o perfil em aminoácidos essenciais ( $\mathrm{g} / 100 \mathrm{~g}$ de proteína bruta) dos três tipos de silagens com o perfil em AAE da farinha de peixe e farelo de soja. Verificase que as silagens ácida, biológica e enzimática apresentaram maiores valores para metionina e histidina e menores valores para a fenilalanina e arginina em relação à farinha de peixe e ao farelo de soja. As silagens evidenciaram maiores teores de triptofano que a farinha de peixe, porém menores que o farelo de soja. Alguns autores realizam a secagem conjunta da silagem com o farelo de soja, pois além de melhorar o perfil de aminoácidos diminui a umidade do produto (VIDOTTI, 2001; FAGBENRO, 1994).

\section{TABELA 2 - COMPOSIÇÃO EM AMINOÁCIDOS ESSENCIAIS (AAE) DAS SILAGENS ÁCIDA, BIOLÓGICA E ENZIMÁTICA, DA FARINHA DE PEIXE E DO FARELO DE SOJA (RESULTADOS EXPRESSOS EM g/100 g DE PROTEÍNA BRUTA)}

\begin{tabular}{lccccc}
\hline $\begin{array}{c}\text { Aminoácidos } \\
\text { Essenciais }\end{array}$ & $\begin{array}{c}\text { Silagem }^{1} \\
\text { biológica }\end{array}$ & $\begin{array}{c}\text { Silagem }^{1} \\
\text { ácida }\end{array}$ & $\begin{array}{c}\text { Silagem }^{1} \\
\text { enzimática }\end{array}$ & $\begin{array}{c}\text { Peixe }^{2} \\
\text { (farinha) }\end{array}$ & $\begin{array}{c}\text { Soja }^{2} \\
\text { (farelo) }\end{array}$ \\
\hline Valina & 4,30 & 5,40 & 5,87 & 5,90 & 4,98 \\
Metionina & 5,62 & 4,34 & 4,35 & 2,43 & 1,09 \\
Isoleucina & 3,64 & 6,46 & 4,35 & 4,80 & 4,88 \\
Leucina & 7,28 & 7,00 & 6,52 & 7,22 & 7,62 \\
Treonina & 4,96 & 4,08 & 4,13 & 4,40 & 3,94 \\
Fenilalanina & 3,97 & 4,10 & 4,35 & 5,22 & 5,05 \\
Lisina & 7,28 & 6,65 & 6,35 & 8,69 & 6,31 \\
Histidina & 2,98 & 2,80 & 2,61 & 2,07 & 2,53 \\
Arginina & 5,62 & 5,80 & 5,87 & 6,59 & 8,12 \\
Triptofano & 0,73 & 0,72 & 0,78 & 0,63 & 1,41 \\
\hline
\end{tabular}

Fonte: ${ }^{1 B O R G H E S I ~(2004) ; ~}{ }^{2}$ PORTZ (2001).

\section{ALIMENTAÇÃO DE ORGANISMOS AQUÁTICOS}

A elaboração de silagens a partir de resíduos da comercialização ou do processamento do pescado, visando sua utilização como ingrediente em rações para a aqüicultura tem sido amplamente estudada. Muitos autores acreditam que devido à semelhança dessa fonte protéica com a matériaprima, a silagem demonstra elevado potencial para sua utilização na aqüicultura. Outros se apóiam em seu baixo custo, principalmente quando comparada à farinha de peixe (FAGBENRO, 1994; FAGBENRO e JAUNCEY, 1995a; FAGBENRO e BELLO-OLUSOJI, 1997; GODDARD e AL-YAHYAI, 2001). 
HONCZARYK e MAEDA (1998) avaliaram o crescimento do pirarucu (Arapaimas gigas), peixe carnívoro de grande importância na região amazônica, com dietas a base de silagem biológica, elaborada com resíduos da filetagem da piramutaba (Brachyplatystoma vaillantii). As dietas a base de ensilado proporcionaram bom crescimento e melhores características de carcaça quando comparadas com dietas a base de peixe picado.

Avaliando o efeito da substiuição da farinha de peixe (FP) por diferentes tipos de silagens na alimentação de girinos de rã-touro (Rana catesbeiana), SECCO, DE STÉFANI e VIDOTTI (2002) testaram 5 dietas experimentais (100\% FP; 50\% FP e 50\% silagem ácida de resíduo da filetagem de tilápia (RTA); 100\% RTA; 50\% FP e 50\% silagem ácida de descarte de peixe inteiro de água doce (ADA); $100 \%$ ADA). Verificaram que a FP pode ser substituída em até $50 \%$, tanto pela RTA quanto pela ADA, em dietas para girinos de rã-touro sem prejuízo no desempenho desses animais.

Em busca de novas alternativas, OLIVEIRA (2003) avaliou o uso da silagem de pescado como palatabilizante para o "black bass" (Micropterus salmoides), comparando-a com o produto comercial FISHARON ${ }^{\circledast}$ (farinha de peixe e proteína solúvel de peixe). Relatou que os peixes alimentados com a dieta contendo o produto comercial obtiveram melhor ganho de peso e conversão alimentar, porém não houve diferença significativa entre os tratamentos $(P>0,05)$. A viabilidade do uso da silagem como palatabilizante torna-se importante pelo alto custo do produto comercial.

Testando a digestibilidade da silagem ácida de sardinha e da farinha de peixe na alimentação da tilápia do Nilo (O. niloticus), GODDARD e AL-YAHYAI (2001) não encontraram diferenças significativas entre os ingredientes mostrando o potencial do uso da silagem como substituto parcial da farinha de peixe. Esses autores encontraram valores do coeficiente de digestibilidade aparente da proteína $\left(\mathrm{CDA}_{\mathrm{PB}}\right)$ de $95,10 \%$.

Estudando o uso da silagem de peixe na alimentação do salmão (Salmo salar), JACKSON, KERR e BULLOCK (1984) não encontraram diferenças significativas no crescimento e conversão alimentar entre as dietas que continham a silagem e a dieta comercial (controle).

FAGBENRO (1994) estudou o desempenho de tilápias do Nilo, alimentadas com dietas contendo silagem biológica de pescado, parcialmente desidratadas por meio da adição de farelo de soja, farinha de vísceras, farinha de penas hidrolisada ou farinha de carne e ossos. Não verificou diferença entre essa e a dieta controle que continha farinha de peixe como principal fonte protéica, indicando a viabilidade do uso da silagem de pescado em rações para a tilápia do Nilo.

Ao avaliar o valor nutricional de dietas contendo silagem biológica de tilápia, parcialmente desidratada com diversos subprodutos na alimentação do bagre africano (Clarias gariepinus),

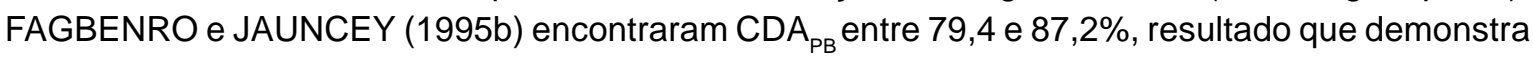
a qualidade do produto.

FAGBENRO e JAUNCEY (1998) utilizaram dietas úmidas para a tilápia do Nilo, compostas de silagem biológica de tilápia misturada com diferentes ingredientes protéicos (farinha de vísceras ou farelo de soja e farinha de penas hidrolisadas ou farinha de peixe). Encontraram valores elevados para $\mathrm{CDA}_{\mathrm{PB}}$ (entre 83,50 e $86,60 \%$ ), CDA da energia bruta (entre 80,60 e $84,80 \%$ ) e matéria seca (entre 82,40 e $85,90 \%$ ).

A utilização de silagens de peixe, parcialmente desidratadas, como fontes alternativas de proteína na alimentação do pacu (Piaractus mesopotamicus) foi estudada por VIDOTTI (2001). Os valores de digestibilidade protéica (entre 74,71 e $83,43 \%$ ) e de retenção protéica foram maiores que os obtidos com a dieta controle, que continha a farinha de peixe como principal fonte protéica, indicando o potencial da silagem como substituto parcial da farinha de peixe em dietas para o pacu.

HOSSAIN, NAHAR e KAMAL (1997) determinaram o coeficiente de digestibilidade aparente (CDA) de várias fontes protéicas de origem animal e vegetal para a carpa indiana (Labeo rohita). Esse estudo mostrou que as silagens ácidas de pescado marinho, produzidas com ácido fórmico ou sulfúrico e parcialmente desidratadas com farinha de trigo, apresentaram os melhores $\mathrm{CDA}_{\mathrm{PB}}$ (88,08 e 85,11\% para as silagens com ácido fórmico e com ácido sulfúrico, respectivamente). Constataram que sob o ponto de vista da digestibilidade, a silagem de pescado pode ser utilizada como fonte protéica para alimentação da carpa indiana. 
Estudando o $\mathrm{CDA}_{\mathrm{PB}}$, CDA dos aminoácidos e da energia $\left(C D A_{E B}\right)$ essenciais da silagem biológica, composta de cabeças de camarão, para a alimentação do bagre africano, FAGBENRO e BELLO-OLUSOJI (1997) consideraram a silagem biológica como boa alternativa de ingrediente protéico para essa espécie. Encontraram valores de $C_{D A}$ de 84,90 e $86,40 \%$ para a SB misturada com farelo de soja e subprodutos de aves, respectivamente.

Utilizando diferentes aglutinantes em dietas úmidas para a tilápia do Nilo, contendo 50\% de silagem biológica de tilápia, FAGBENRO e JAUNCEY (1995a) obtiveram valores de digestibilidade para lipídios entre 65,90 e 78,20\% e matéria seca entre 73,40 e 84,30\%.

STONE e HARDY (1986) testaram a digestibilidade da silagem ácida na alimentação da truta arco-íris, utilizando o método de extrusão manual para coleta de fezes e obtiveram valor de $88,70 \%$ para o $\mathrm{CDA}_{\mathrm{PB}}$. HARDY, SHEARER e SPINELLI (1984) também utilizando a silagem ácida na alimentação da truta arco-íris encontraram CDA ${ }_{P B}$ de 80,10\%.

Os coeficientes de digestibilidade aparente de silagens ácidas e biológicas, preparadas a partir de diferentes matérias-primas (resíduos comerciais de peixes marinhos, de peixes de água doce e resíduos da filetagem da tilápia do Nilo) para pacu foram avaliados por VIDOTTI, CARNEIRO e VIEGAS (2002). Os autores obtiveram altos valores para $\operatorname{CDA}_{\mathrm{PB}}(72,5 \mathrm{a} 88,11 \%)$, fato que aponta a viabilidade do uso da silagem em dietas para organismos aquáticos.

Estudando o valor nutricional de dietas contendo silagem biológica de pescado, parcialmente desidratadas, pela adição de farelo de soja, resíduo de aves ou farinha de carne e ossos, FAGBENRO, JAUNCEY e HAYLOR (1994) não constataram diferenças significativas nos parâmetros de desempenho e de utilização da proteína em relação à dieta composta por farinha de peixe. $O$ experimento mostrou que essas dietas, principalmente a composta por silagem e farelo de soja, podem ser utilizadas na alimentação de tilápias do Nilo (onívora) e bagre Africano (carnívoro) sem que o desempenho, a utilização da proteína e a composição da carcaça sejam afetados.

HERAS, MCLEOD e ACKMAN (1994) relataram que salmões (Salmo salar) alimentados com silagem ácida, preparada com resíduos de dogfish (Squalus acanthias), apresentaram bom ganho de peso, conversão alimentar e taxa de eficiência protéica quando comparada com dieta controle contendo como principal fonte protéica a farinha de arenque. A análise sensorial dos filés não demonstrou diferenças significativas no sabor da carne.

CARVALHO et al. (2006) avaliaram o desempenho de alevinos de tilápia do Nilo que receberam dietas contendo 0, 10, 20 e 30\% de silagem de pescado, acrescida de $30 \%$ de farelo de trigo. Não observaram diferença entre as dietas que continham silagem sobre o ganho de peso, conversão alimentar aparente e taxa de eficiência protéica, afirmando que a inclusão de até $30 \%$ dessa silagem na alimentação de alevinos de tilápia do Nilo não causa prejuízo no desempenho dos animais.

Trutas arco-íris (Oncorhynchus mykiss) apresentaram maior ganho de peso, taxa de eficiência protéica e digestibilidade aparente $\left(C A_{P B}=94,00 \%\right)$, quando alimentadas com silagens ácidas em que a hidrólise durou de 3 a 7 dias do que com silagens ácidas obtidas após autólise de 42 dias (STONE et al., 1989).

BORGHESI (2004) determinou o coeficiente de digestibilidade aparente (CDA) dos nutrientes das silagens ácida (SA), biológica (SB) e enzimática (SE) para tilápia do Nilo, obtendo valores de: 92,01; 89,09 e 93,66\% para proteína bruta, 86,39; 84,53 e 89,09\% para energia bruta, 82,52; 78,98 e $82,96 \%$ para matéria seca, 81,$72 ; 73,99$ e 80,27\% para cálcio e 77,$86 ; 79,21$ e 81,46\% para o fósforo, respectivamente. O CDA médio dos aminoácidos foi de 91,83; 90,76 e 94,61\% para SA, SB e SE, respectivamente. Com base nos resultados recomendou o uso das silagens ácida, biológica e enzimática como ingrediente protéico em rações para a tilápia do Nilo.

Abordando outra forma de utilização da silagem de peixe em rações para a aqüicultura, MAIA et al. (1998) caracterizaram a fração lipídica de silagens de resíduos de tilápia. Afirmaram que o óleo obtido do processo de silagem constitui fonte de lipídios insaturados de alta qualidade e baixo custo, porém o perfil de ácidos graxos tende a variar de acordo com a matéria-prima utilizada na elaboração da silagem. 


\section{CONSIDERAÇÕES FINAIS}

Os resultados dispostos na literatura, tanto nacional quanto internacional, mostram a silagem de pescado como ingrediente (alternativo) potencial para ser utilizado em rações para aqüicultura. Porém, deve-se ressaltar que a escala de produção das silagens em experimentos é relativamente pequena (até 60k g), não sendo produzida de forma contínua em escala industrial. Sugere-se a análise da composição química da silagem antes de seu uso como ingrediente em rações, devido a grande variação de composição da matéria-prima utilizada (espécie, sexo, época do ano). Sugerese também estudo objetivando avaliar o custo de produção e o custo do transporte, ou seja, quanto custa para transportar um quilo de proteína devido ao volume (quantidade de água) do produto. A partir da realização dessas etapas ter-se-á argumentos mais sólidos para a utilização desse produto.

\section{ABSTRACT}

FISH SILAGE IN THE FEEDING OF AQUATIC ORGANISMS

The objective of this work was to evaluate the potential of the fish silage as an alternative ingredient to fish meal, main source of protein, in rations for aquaculture, based on the review of many papers of both national and international literature. The work approached the biochemistry, production methodologies, nutritional aspect and the use of the silage in the feeding of aquatic organisms as well as results of many researches. The utilization of the fish silage as an ingredient (alternative) potential to be used in rations for aquaculture is viable and, therefore, the scientific investigations must continue in this sense.

KEY-WORDS: WASTE; SILAGE; PROTEIN; FISH NUTRITION; ALTERNATIVE INGREDIENT.

\section{REFERÊNCIAS}

1 BEERLI, E.L.; BEERLI, K.M.C.; LOGATO, P.V.R. Silagem ácida de resíduos de truta (Oncorhynchus mykiss), com utilização de ácido muriático. Ciência e Agrotecnologia, v.28, n.1, p. 195-198, 2004.

2 BERENZ, Z. Utilización del ensilado de residuos de pescado en pollos. Disponível em: <http://www.fao.org/waicent/ faoinfo/cap2.htm>. 1994. 11 p. Acesso em: 25 fev. 2003.

3 BORRENSEN, T. Biotechnology, by products and aquaculture. In: BLIGH, E.G (ed.). Seafood science and technology. Surrey: Fishing News Books, 1990. p. 278-287.

4 BORGHESI, R., Avaliação físico-química, nutricional e biológica das silagens ácida, biológica e enzimática elaboradas com descarte e resíduo do beneficiamento da tilápia do Nilo (Oreochromis niloticus). Piracicaba, 2004. 96 f. Dissertação (Mestrado em Ciência e Tecnologia de Alimentos), Departamento de Agroindústria, Alimentos e Nutrição, Universidade de São Paulo.

5 CARVALHO, G.G.P.; PIRES, A.J.V.; VELOSO, C.M.; SILVA, F.F.; CARVALHO, B.M.A. Silagem de resíduo de peixe em dietas para alevinos de tilápia-do-nilo. Revista Brasileira de Zootecnia, v.35, n.1, p. 126-130, 2006.

6 CHENG, Z.J.; HARDY, R.W.; USRY, J.L. Effects of lysine supplementation in plant protein-based diets on the performance of rainbow trout (Oncorhynchus mykiss) and apparent digestibility coefficients of nutrients. Aquaculture, v.215, p. 255-265, 2003.

7 DAPKEVICIUS, M.L.E.; NOUT, R.M.J.; ROMBOUTS, F.M.; HOUBEN, J.H.; WYMENGA, W. Biogenic amine formation and degradation by potential fish silage starter microorganisms. International Journal of Food Microbiology, v.57, p. 107-114, 2000.

8 DISNEY, J.G.; TATTERSON, I.N.; OLLEY, J. Recent developments in fish silage. In: CONFERENCE ON THE HANDLING, PROCESSING AND MARKETING OF TROPICAL FISH, London, 1976. Proceedings... London: Ministry of Oversea Development, 1977. p.321- 340.

9 EL-SAYED, A.F.M. Alternative dietary protein sources for farmed tilapia, Oreochromis spp. Aquaculture, v.179, p. 149168, 1999.

10 ESPE, M.; LIED, E. Fish silage prepared from different cooked and uncooked raw materials: chemical changes during storage at different temperatures. Journal of the Science Food and Agriculture, v.79, p. 327-332, 1999. 
11 ESPE, M.; RAA, J.; NJAA, L.R. Nutritional value of stored fish silage as a protein source for young rats. Journal of the Science Food and Agriculture, v.49, p. 259-270, 1989.

12 ESPÍNDOLA FILHO, A. Aproveitamento do resíduo sólido de peixe, camarão e bivalves como ingrediente de ração para aqüicultura. São Paulo, 1999. 224 f. Tese (Doutorado em saneamento ambiental), Universidade Mackenzie.

13 FAGBENRO, O. Dried fermented fish silage in diets for Oreochromis niloticus. The Israeli Journal of Aquaculture, v.46, n.3, p.140-147, 1994.

14 FAGBENRO, O.; JAUNCEY, K.; HAYLOR, G. Nutritive value of diets containing dried lactic acid fermented fish silage and soybean meal for juvenile Oreochromis niloticus and Clarias gariepinus. Aquatic Living Resource, v.7, p. 79-85, 1994.

15 FAGBENRO, O.; JAUNCEY, K. Water stability, nutrient leaching and nutritional properties of moist fermented fish silage diets. Aquaculture Engineering, v.14, p. 143-153, 1995a.

16 FAGBENRO, O.; JAUNCEY, K. Growth and protein utilization by juvenile catfish (Clarias gariepinus) feed dry diets containing co-dried lactic-acid-fermented fish-silage and protein feedstuffs. Bioresource Technology, v.51, p. 59-35, $1995 b$.

17 FAGBENRO, O.; JAUNCEY, K. Physical and nutritional properties of moist fermented fish silage pellets as a protein supplement for tilapia (Oreochromis niloticus). Animal Feed Science and Technology, v.71, p. 11-18, 1998.

18 FAGBENRO, O.; BELLO-OLUSOJI, O.A. Preparation, nutrient composition and digestibility of fermented shrimp head silage. Food Chemistry, v.60, p. 489-493, 1997.

19 FERRAZ DE ARRUDA, L. Aproveitamento do resíduo do beneficiamento da tilápia do Nilo (Oreochromis niloticus) para obtenção de silagem e óleo como subprodutos. Piracicaba, 2004. 78 f. Dissertação (Mestrado em Ciência e Tecnologia de Alimentos), Departamento de Agroindústria, Alimentos e Nutrição, Universidade de São Paulo.

20 FURUYA, W.M. Digestibilidade aparente de aminoácidos e substituição da proteína da farinha de peixe pela do farelo de soja com base em proteína ideal em rações para a tilápia do Nilo (Oreochromis niloticus). Botucatu, 2000. 69 f. Tese (Doutorado em Zootecnia), Universidade Estadual Paulista.

21 GODDARD, J.S.; AL-YAHYAI, D.S.S. Chemical and nutritional characteristics of dried sardine silage. Journal of Aquatic Food Product Technology, v.10, n.4, p. 39-50, 2001.

22 GODDARD, J.S.; PERRET, J.S.M. Co-drying fish silage for use in aquafeeds. Animal Feed Science and Technology, v.118, p. 337-342, 2005.

23 HARDY, R.W.; SHEARER, K.D.; SPINELLI, J. The nutritional properties of co-dried fish silage in rainbow trout (Salmo gairdinieri) dry diets. Aquaculture, v.38, p. 35-44, 1984.

24 HERAS, H.; MCLEOD, C.A.; ACKMAN, R.G. Atlantic dogfish silage vs. herring silage in diets for Atlantic salmon (Salmo salar): growth and sensory evaluation of fillets. Aquaculture, v. 125, p. 93-103, 1994.

25 HONCZARYK, A.; MAEDA, L.S. Crescimento do pirarucu, Arapaima gigas, utilizando dieta à base de ensilado biológico de pescado. In: SIMPÓSIO BRASILEIRO DE AQÜICULTURA, 10., Recife. Anais... Recife: Persona, 1998. v.2, p.93100.

26 HOSSAIN, M.A.; NAHAR, N.; KAMAL, M. Nutrient digestibility coefficients of some plant and animal proteins for rohu (Labeo rohita). Aquaculture, v.151, p. 37-45, 1997.

27 JACKSON, A.J.; KERR, A.K.; BULLOCK, A.M. Fish silage as a dietary ingredient for salmon. II. Preliminary growth findings and nutritional pathology. Aquaculture, v.40, p. 283-291, 1984.

28 KOMPIANG, I.P. Fish silage: its prospect and future in Indonesia. Indonesian Agriculture Resource \& Development Journal, v.3, n.1, p. 9-12, 1981.

29 MAIA, W.M.; NUNES, M.L.; FIGUEIREDO, M.J.; BRAGAGNOLO, N. Caracterização da fração lipídica de silagem de resíduos de tilápia para utilização em rações para a aqüicultura. In: SIMPÓSIO BRASILEIRO DE AQÜICULTURA, 10., Recife. Anais... Recife: Persona, 1998. v.2, p.55-64.

30 MORALES-ULLOA, D.F. Bioconversão de resíduos da indústria pesqueira. Piracicaba, 1994. 127 f. Dissertação (Mestrado em Ciência e Tecnologia de Alimentos), Departamento de Agroindústria, Alimentos e Nutrição, Universidade de São Paulo.

31 NELSON, D.L.; COX, M.M. Lehninger: principles of biochemistry. New York: Worth Publishing, 2000.145 p.

32 NEW, M.; CSAVAS, I. Will there be enough fish meal for fish meals? Aquaculture Europe, v.19, n.3, p. 6-13, 1995.

33 OETTERER, M. Agroindústrias beneficiadoras de pescado cultivado: unidades modulares e polivalentes para implantação, com enfoque nos pontos críticos higiênicos e nutricionais. Piracicaba, 1999. 196 f. Tese (Livre-Docência), Departamento de Agroindústria, Alimentos e Nutrição, Universidade de São Paulo. 
34 OETTERER, M. Produção de silagem a partir da biomassa residual de pescado. Alimentos e Nutrição, v.5, p. 119-134, 1994.

35 OLIVEIRA, A.M.B.M.S. Substituição de fontes protéicas de origem animal por fontes protéicas de origem vegetal em rações para o "black bass" Micropterus salmoides. Piracicaba, 2003. 103 f. Tese (Doutorado em Zootecnia), Departamento de Zootecnia, Universidade de São Paulo.

36 PEZZATO, L.E. Alimentos convencionais e não-convencionais disponíveis para a indústria da nutrição de peixes e crustáceos. In: SIMPÓSIO INTERNACIONAL SOBRE NUTRIÇÃO E PEIXES E CRUSTÁCEOS, 1., Campos do Jordão, 1995. Anais... Campinas: CBNA, 1995. p.34-52.

37 PORTZ, L. Utilização de diferentes fontes protéicas em dietas formuladas pelo conceito de proteína ideal para o "black bass" (Micropterus salmoides). Piracicaba, 2001. 111 f. Tese (Doutorado em Zootecnia), Departamento de Zootecnia, Universidade de São Paulo.

38 RAA, J.; GILDBERG, A. Fish silage: a review. Journal of the Food Science and Nutrition, v.61, p.383-419, 1982.

39 SALES, R.O. Processamento, caracterização química e avaliação nutricional da silagem da despesca da tilápia do Nilo (Oreochromis niloticus) em dietas experimentais com ratos. Campinas, 1995. 174 f. Tese (Doutorado em Engenharia de Alimentos), Universidade de Campinas.

40 SALES, J.; BRITZ, P.J. Apparent and true availability of amino acids from common feed ingredients for South African abalone (Haliotis midae L.). Aquaculture Nutrition, v.9, p. 55-64, 2003.

41 SECCO, E.M.; DE STÉFANI, M.V.; VIDOTTI, R.M. Substituição da farinha de peixe pela silagem de peixe na alimentação de girinos de rã-touro (Rana catesbeiana). Ciência Rural, v.32, n.3, p. 505-509.

42 SHIRAI, K.; GUERRERO, I.; HUERTA, S.; SAUCEDO, G.; CASTILLO, A.; GONZALEZ, R.O.; HALL, G.M. Effect of initial glucose concentration and inoculation level of lactic acid bacteria in shrimp waste ensilation. Enzyme and Microbial Technology, v.28, p. 446-452, 2001.

43 STONE, F.E.; HARDY, R.W. Nutritional value of acid stabilized silage and liquefied fish protein. Journal of the Science of Food and Agriculture, v.37, p.797-803, 1986.

44 STONE, F.E.; HARDY, R.W.; SHEARER, K.D.; SCOTT, T.M. Utilization of fish silage by rainbow trout (Salmo gairdineri). Aquaculture, v.76, p. 109-118, 1989.

45 TOCHER, D.R.; MOURENTE, G.; SARGENT, J.R. The use of silages prepared from fish neural tissues as enrichers for rotifers (Brachionus plicatilis) and Artemia in the nutrition of larval marine fish. Aquaculture, v.148, p. 213-231, 1997.

46 VALÉRIO, A.C.R. Elaboração de silagem enzimática de pescado como alternativa ao processo tradicional. Piracicaba, 1994. 102 f. Dissertação (Mestrado em Ciência e Tecnologia de Alimentos), Departamento de Agroindústria, Alimentos e Nutrição, Universidade de São Paulo.

47 VIANA, M.T.; GUZMAN, J.M.; ESCOBAR, R. Effect of heated and unheated fish silage as a protein source in diets for abalone Haliotis fulgens. Journal of the World Aquaculture Society, v.30, n.4, p.481-489, 1999.

48 VIDOTTI, R.M. Produção e utilização de silagens de peixe na nutrição do pacu (Piaractus mesopotamicus). Jaboticabal, 2001. 65 f. Tese (Doutorado em Aqüicultura), Universidade Estadual Paulista.

49 VIDOTTI, R.M.; CARNEIRO, D.J; VIEGAS, E.M.M. Acid and fermented silage characterization and determination of apparent digestibility coefficient of crude protein for pacu Piaractus mesopotamicus. Journal of the World Aquaculture Society, v.33, n.1, p. 57-62, 2002.

50 VIDOTTI, R.M.; VIEGAS, E.M.M.; CARNEIRO, D.J. Amino acid composition of processed fish silage using diferent raw materials. Animal Feed Science and Technology, v.105, p.199-204, 2003.

51 ZAHAR, M.; BENKERROUM, N.; GUEROUALI, A.; LARAKI, Y.; El-YAKOUBI, K. Effect of temperature, anaerobiosis, stirring and salt addition on natural fermentation silage of sardine and sardine wastes in sugarcane molasses. Bioresource Technology, v.82, p. 171-176, 2002.

\section{AGRADECIMENTOS}

Coordenação de Aperfeiçoamento de Pessoal de Nível Superior - CAPES.

Fundação de Amparo à Pesquisa do Estado de São Paulo - FAPESP. 